\title{
Dentro e fora da escola Comparando modos de se relacionar em uma comunidade do Tapajós (Pará, Brasil)
}

\section{( Chantal Medaets ${ }^{1}$ \\ 1 Universidade Estadual de Campinas (Unicamp), Campinas, Brasil ORCiD orcid.org/oooo-0002-7834-3834 \\ Correo electrónico: chantalm@unicamp.br}

Recibido:

og de mayo de 2019 Aceptado:

15 de octubre de 2019

doi: 10.34096/runa.v4oi2.6198

\section{Resumo}

O artigo apresenta uma comparação entre modalidades de aprendizagem e códigos de conduta que regem as relações fora do espaço escolar, nas interações cotidianas de uma comunidade da região do Baixo Tapajós, e aquelas que ocorrem dentro da escola. As práticas de transmissão e aprendizagem em casa e na comunidade são as mesmas ou informam aquelas mobilizadas no contexto escolar? Os resultados preliminares da pesquisa, que ainda está em curso, indicam que há diferenças significativas nos modos de se relacionar nos dois espaços e que professores e alunos parecem transitar entre eles sem demonstrar maiores conflitos.

\section{Dentro y fuera de la escuela: comparando modos de relacio- narse en una comunidad del Tapajós (Pará, Brasil)}

\section{Resumen}

El artículo presenta una confrontación entre modalidades de aprendizaje y códigos de conducta que rigen las relaciones fuera del espacio escolar, en las interacciones cotidianas de una comunidad de la región del Bajo Tapajós, y aquellas que ocurren dentro de la escuela. ¿Las prácticas de transmisión y aprendizaje en la familia y en la comunidad son las mismas o informan a las personas movilizadas en el contexto escolar? Los resultados preliminares de la investigación-que aún está en curso-indican que hay diferencias significativas en los modos de relacionarse en los dos espacios, y que profesores y alumnos parecen transitar entre ellos sin demostrar mayores conflictos.

\section{Palavras-chave}

Aprendizagem; Escola; Populações ribeirinhas; Indígenas do Baixo Tapajós; Formação de professores

\section{Palabras clave}

Aprendizaje; Escuela; Poblaciones ribereñas; Indígenas del Bajo Tapajós; Formación de maestro 


\title{
Learning at school and outside: comparing interactive styles in a community of Tapajós (Pará, Brazil)
}

\begin{abstract}
Key words

Learning practices; Schooling; Brazilian river-dwellers; Indigenous peoples; Teachers' training

In this paper I compare learning modalities and codes of conduct that govern relations outside the school space, in the daily interactions of a community in the Lower Tapajós region, and those that occur within the school. Are transmission and learning practices in the community and family life the same or do they inform those mobilized in the school setting? The preliminary results indicate that there are significant differences in the patterns of interaction in both spaces and that teachers and students seem to shift from one pattern to the other without demonstrating conflicts.
\end{abstract}

\section{Introdução}

Meus primeiros contatos com os moradores da região do Baixo Tapajós, nas proximidades da cidade de Santarém (Pará), datam de 2006. Naquela época eu fui coordenadora pedagógica de escolas localizadas nas zonas rurais do município de Belterra. Éramos então uma equipe de técnicos da prefeitura a realizar "visitas técnicas" às comunidades da região. Cada comunidade nos recebia uma ou duas vezes por ano (em função da disponibilidade orçamentária da prefeitura), chegávamos de barco e ali ficávamos um ou dois dias, dormindo no próprio barco ou hospedados pelos moradores. Durante a estadia, além de resolver problemas administrativos das escolas, nós conversávamos com professores, pais, crianças, realizávamos reuniões e assistíamos a algumas aulas.

A distância e a desconexão que pode haver entre o que se ensina em sala de aula e o que acontece fora dela, é um lugar comum. Escolas foram, um sem número de vezes, apontadas como o lócus da transmissão de conteúdos descontextualizados. As escolas que conheci ali, com notáveis exceções, não escapavam a esse diagnóstico. Penso por exemplo numa escola localizada a oito horas de barco da cidade de Santarém onde, durante a semana de meio ambiente, havia sido feita com os alunos uma faixa que reivindicava: "Queremos ar puro!". Outros problemas ambientais se impunham aos moradores daquela comunidade: a contaminação dos peixes pelo mercúrio que desce do Tapajós em função do garimpo nas proximidades de Itaituba, a ameaça de grupos madeireiros sobre as áreas de floresta do entorno das comunidades, a difícil gestão do lixo em locais sem sistemas públicos de coleta, entre outros. Mas a equipe havia decido abordar um dos temas sugeridos em livros didáticos a sua disposição, a poluição do ar, tema que não era um problema para comunidade escolar em questão. Provocada por diversas situações desse tipo, minha curiosidade se voltou para o espaço fora da escola. Se o que era discutido na escola parecia descolado da realidade cotidiana das crianças e dos adultos da região, que saberes eram de fato valorizados, transmitidos e aprendidos para além dos muros das escola, no cotidiano dessas comunidades? E como aconteciam esses processos de transmissão e aprendizagem?

Essas foram as perguntas que busquei responder no meu doutorado em Antropologia. Começarei assim por apresentar, de maneira bastante sucinta, seus principais resultados. Em seguida, o propósito desse artigo é de "voltar 
à escola", e confrontar os resultados da pesquisa fora dela com um novo trabalho de campo, ainda em curso, realizado desta vez dentro das salas de aula. Em 2016, integrei durante dois meses o cotidiano de duas escolas vizinhas de uma comunidade da região, observando aulas e conversando com professores e alunos. $\mathrm{O}$ interesse de apresentar os resultados ainda preliminares dessa investigação, que necessita ser continuada e aprofundada, é o de explorar uma primeira camada de percepções sobre as práticas dessas pessoas, dentro e fora da escola. Vale destacar desde já que os professores em questão não vem de contextos socioculturais distintos dos das crianças, mas são, ao contrário, moradores antigos das comunidades.

Tendo já examinado com mais detalhe as modalidades de aprendizagem não escolares na região, entro em sala de aula informada e formada por esta primeira pesquisa etnográfica na região. A partir, portanto, desta perspectiva cruzada, já é possível notar que i) há diferenças significativas entre o código de conduta que rege as modalidades de transmissão e aprendizagem fora da escola e aquele que preside as relações dentro dela; ii) ao que tudo indica, professores e crianças transitam entre esses dois modos de interagir sem demonstrar dificuldade.

Por fim, concluo explorando algumas chaves analíticas para pensar a comparação entre "lógicas de interação" (Rockwell, 2018, p. 220) dentro e fora da sala de aula.

\section{Aprender fora da escola}

Como em muitos outros lugares em que as crianças não são excluídas dos espaços de trabalho dos pais e de outros adultos, no Tapajós, meninas e meninos aprendem muita coisa observando e ajudando nas atividades dos adultos. Saberes e habilidades ligados à pesca, à caça e ao cultivo de roçados, assim como a prática de narrar histórias, atividades comuns neste contexto, são assim aprendidas, aos poucos, através dessa observação, da escuta e da participação gradual nas atividades. Diversos autores descreveram e refletiram sobre esse tipo de aprendizagem "por participação" (Lave, 1988; Rogoff, Paradise, Arauz, Correa-Chávez e Angelillo, 2003; Tassinari, 2015; Sautchuk, 2015; Silva e Gomes, 2015). ${ }^{1}$ Um dos pontos que parece ser comum a este tipo de aprendizagem, ocorrendo em muitos lugares diferentes, é o fato de que as pessoas mais experientes permitem que os mais novos (ou menos experientes) participem de uma determinada atividade na medida que eles conseguem de fato ajudar, ou pelo menos não atrapalhar a atividade em curso. Ou seja, a preocupação dos mais experientes não é, em primeira instância, uma preocupação pedagógica, que considera a "ajuda" dos novatos como uma maneira de formálos. Esse pode ser um objetivo secundário, uma espécie de "efeito colateral" positivo, mas raramente é sua intenção principal. Isto implica que, para participar da atividade, a pessoa menos experiente tem que ser capaz de oferecer uma ajuda minimamente eficiente, e não uma pseudo-ajuda cuja verdadeira finalidade fosse pedagógica. Mas esta característica geral da modalidade de aprendizagem "por participação" encontra, como era de se esperar, declinações e variações nos diversos contextos em que ela ocorre.

Alguns dos estudiosos dessa questão descrevem adultos que esperam essa ajuda efetiva dos mais novos, mas são, ainda assim, tolerantes com seus erros e bastante conscientes da importância dessa participação para a formação dos novatos (Paradise e Rogoff, 2009). Já em outros contextos, ${ }^{2}$ e esse é o caso do
1. Para uma revisão bibliográfica sobre o tema, ver Medaets (2015).

2. Como por exemplo nas ilhas de Samoa (Odden, 2007) ou em famílias que vivem da exploração de Salinas, no oeste da França (Delbos e Jorion, 1984). 
3. A folha da palmeira de curuá, muito usada nas construções locais, precisa ser manipulada ("aberta"), antes de integrar telhados ou paredes das casas.

4. Sobre os dispositivos disciplinares e o esforço constante dos adultos para manter essa ordem hierárquica, ver Medaets (2013, 2017).
Tapajós, os adultos - e as pessoas mais experientes de maneira geral (crianças que dominam melhor que outras uma determinada atividade, por exemplo) - mostram pouquíssima empatia e paciência com os menos experientes. $\mathrm{O}$ menor titubeio ou gesto considerado mal feito é suficiente para que se afaste um filho que queria "abrir palha" ${ }^{3}$ junto com outros membros da família ou, entre crianças, para excluir do jogo um amigo. Não é comum corrigir, guiar, oferecer suporte ao aprendiz, mas afastar, excluir. Os que estão na posição de aprendizes percebem então rapidamente que para aprender devem contar com sua própria iniciativa, com sua capacidade de observação e escuta e com momentos de experimentação entre pares. Esta postura não se restringe a processos de aprendizagem ligados a atividades produtivas, mas é também observada em práticas lúdicas e narrativas.

Soma-se a isso, regras de conduta das relações intergeracionais na região segundo as quais os mais velhos devem ser respeitados, e mesmo temidos, e, idealmente, jamais interrompidos ou atrapalhados. Respeitar, na região, implica uma atitude de deferência em relação aos mais velhos, em especial os da sua família. Filhos, netos, sobrinhos e afilhados (ou seja, descendentes diretos e colaterais) devem pedir a benção sempre que encontram familiares da geração acima da sua - e o fazem efetivamente. As desobediências ou resistências das crianças são punidas com broncas ("ralhos") que, se se mostrarem ineficazes, serão seguidas de punição física. ${ }^{4} \mathrm{O}$ tom das falas dirigidas às crianças, sejam elas familiares ou não, é ríspido e é incomum que adultos peçam opinião de crianças e jovens para qualquer que seja o assunto, mesmo quando a questão os concerne diretamente.

O que se vê, então, fora da escola, são crianças - e também aprendizes jovens e adultos - que não têm o hábito de fazer perguntas, de pedir ajuda, ou de vir mostrar aos mais velhos suas descobertas. São perspicazes observadores e têm o costume de escutar em silêncio. E pode-se vê-los experimentando performances que ainda não estão seguros de dominar na companhia de parceiros com um nível de competência próximo ao seu. Esses são alguns dos traços gerais da postura daqueles que estão na posição de aprendiz na região do Baixo Tapajós. Eles foram apresentadas aqui de forma sucinta e separadas do material etnográfico que sustenta as análises, o leitor as encontrará em Medaets $(2015,2016)$. Vejamos, a seguir, como se desenham as relações entre adultos, crianças e jovens dentro da escola.

\section{Aprender em sala de aula}

\section{Escolas}

Em 2016 voltei a campo e, além de apresentar e discutir com meus interlocutores os resultados da pesquisa doutoral, iniciei uma nova pesquisa, nas escolas. Em uma das comunidades que havia trabalhado, ${ }^{5}$ acompanhei as aulas nas duas unidades escolares municipais ali presentes. Uma delas era uma escola indígena, com uma única turma multisseriada de 18 alunos do $1^{\circ}$ ao $5^{\circ}$ ano e quatro alunos menores, os "encostados" (não oficialmente inscritos). ${ }^{6} \mathrm{~A}$ escola funcionava numa sala com piso de cimento, teto de palha e cercada de madeira. Os pais a haviam construído com materiais em grande parte fornecidos pela prefeitura (com exceção da palha, colhida no local). Não havia, até aquele momento, cozinha e banheiros, a merenda era distribuída entre as famílias e as crianças iam até suas casas no intervalo para lanchar. Mas os pais estavam mobilizados para lutar pela construção de uma "escola padrão", com 
um prédio similar ao da outra escola da comunidade. Esta outra, uma escola regular, funcionava então nos desejados moldes da "escola padrão": piso de cimento, telhado de telhas de barro, paredes de tijolos (furados, para facilitar a aeração), portas com chaves. Além das três salas de aula, havia banheiros, uma cozinha e uma pequena sala para a secretaria. Funcionavam ali três turmas também multisseriadas. Uma com 20 alunos do $1^{\circ}$ ao $5^{\circ}$ ano e cinco "encostados", outra com 16 alunos do $6^{\circ}$ e $7^{\circ}$ ano e uma terceira turma, com 12 alunos do $8^{\circ}$ e $9^{\circ}$ ano. Nas duas escolas, as aulas das turmas do Fundamental I (1ㅜ․ ao 5 ano) ocorriam pela manhã. As aulas das outras duas turmas de mais velhos, ambas na escola regular, ocorriam à tarde. Durante dois meses assisti as aulas alternando uma semana em cada turma, nas duas escolas.

Meu objetivo principal com essa incursão etnográfica foi de confrontar o que tinha observado fora da sala de aula com as práticas no interior da escola. As estratégias utilizadas por professores e crianças, todos nascidos e criados na comunidade, para ensinar e aprender em casa e na comunidade são as mesmas ou informam aquelas mobilizadas no contexto escolar? Em que medida as "lógicas de interação" (Rockwell, 2018) mais habituais entre crianças e adultos observadas fora da escola estão presentes no interior destas instituições? O fato, por exemplo, das crianças raramente pedirem ajuda ou de não interromperem os adultos, seriam comportamentos reproduzidos dentro da escola? Buscando responder essas perguntas, apresentarei um quadro geral da rotina nas escolas. A descrição das principais características da formação dos professores será importante para entendermos como tem se construído essa relação na escola.

Um ponto de esclarecimento se faz necessário sobre o fato de se tratar de uma escola indígena e outra não. A auto identificação enquanto indígena ${ }^{7}$ não é consensual na comunidade, como é o caso em tantas outras comunidades na região (ver sobre esse ponto, Vaz, 2010 ou Mahalem de Lima, 2015). Há membros das mesmas famílias que têm opiniões opostas a respeito e, enquanto alguns "se assumem" ${ }^{8}$ indígenas, outros recusam categoricamente a fazê-lo. Nas escolas há, por hora, poucas diferenças tanto nas práticas docentes quanto discentes. Dois pontos de distinção devem ser no entanto mencionados. As professoras do Ensino Fundamental I costumam começar as aulas cantando uma música junto com as crianças. Na escola indígena muitas vezes trata-se de uma canção oriunda do repertório do movimento indígena na região, ${ }^{9}$ às vezes cantada em Nheengatu. ${ }^{10}$ Outro ponto, os pais que se uniram para criar a escola indígena buscavam, naquele momento, apoio da prefeitura para a contratação de um professor de Nheengatu. A valorização da língua nativa parece então estar no centro das preocupações daquele coletivo indígena, como tem acontecido em outros lugares (Álvares, 2004; Santana e Cohn, 2016; Shulist, 2018).

\section{Professores e sua formação}

Quatro professores atuavam nas duas escolas da comunidade. Vânia ${ }^{11}$ (34 anos) dava aulas na escola indígena de manhã e à tarde assumia a turma de $8^{\circ}$ e $9^{\circ}$ anos na escola regular. Laurinda, Carmem e Carlos (45, 51 e 28 anos respectivamente) trabalhavam somente na escola regular. Todos tinham cursado ou estavam cursando ensino superior. Vânia e Laurinda já tinham uma primeira graduação realizada em uma universidade particular que oferece cursos à distância na região, Vânia em Letras e Laurinda em Pedagogia. Estavam naquele momento realizando uma segunda graduação, Laurinda em Geografia e Vânia em História, oferecida pela Universidade Federal do Pará (UFPA), no âmbito do Plano Nacional de Formação de Professores da Educação
7. Observando o cuidado com anonimato das pessoas mencionadas no texto, não especificarei a etnia que reivindicam integrar pois esta explicitação tornaria a comunidade (e por conseguinte seus professores) identificável.

8. Termo utilizado pelos integrantes do movimento indígena.

9. Por exemplo: “Tupã está na terra, tupã está no ar...” ou "Chibé poranga, poranga..."

10. Nheengatu ou língua geral é uma língua de base tupi, criada por missionários no século XVII para facilitar a comunicação entre índios de diferentes etnias que conviviam nas missões. Ela tornou-se mais tarde a língua de alguns povos que deixaram de falar sua língua original, como é o caso de algumas etnias no Alto e Médio Rio Negro. No Tapajós, o Nheengatu não é mais falado mas muitas palavras e expressões foram incorporadas no português local.

11. Todos os nomes próprios apresentados no artigo foram alterados. 
12. Os cursos do PARFOR se concentram no período de férias. Cada professor universitário permanece por volta de uma semana na localidade em que ocorre o curso (para a região, a cidade de Santarém ou comunidade de Cametá) e oferece aproximadamente 60 horas de sua disciplina. As disciplinas e professores se sucedem assim em janeiro, fevereiro e julho. Para uma descrição geral do PARFOR ver: http://www.capes.gov.br/educacao-basica/parfor. E para uma descrição do PARFOR na UFPA ver: https://www.aedi.ufpa.br/parfor/
Básica (PARFOR) ${ }^{12}$ Carmem havia concluído Pedagogia em 1989, num curso oferecido na região pela UFPA. Enfim, Carlos fazia graduação em Educação Física também no curso que a UFPA oferecia na região através do PARFOR.

Nos cursos do PARFOR/UFPA, segundo estes professores, falava-se muito em abandonar um ensino "só puramente tradicional", que eles entendiam como a prática "do professor passar o assunto no quadro e os alunos ficarem só tirando [copiando]". Os quatro professores, e como maior ênfase as duas mais velhas, afirmavam ter sido essa a sua experiência enquanto alunos, na Educação básica.

Porque no nosso tempo, era assim. Até hoje eu tenho dificuldade de interpretação de texto, porque meus professores eram desses tradicionais mesmo. Era só passar o conteúdo no quadro. Quando foi no ensino médio, uma vez, um professor me pediu pra dizer o que estava escrito. Eu soava frio! Soava mesmo... Nunca tinha feito, como eu ia saber? (Laurinda, 45 anos)

Durante as graduações que realizaram ou estavam realizando, os professores diziam ser estimulados a mudar essa postura. "Todos eles na universidade falam muito pra gente, pra discutir com os alunos sobre o que é aquilo que eles estão lendo, pra fazer jogos, rodas de conversa..." (Vânia). Esse grupo de professores parece de fato ter incorporado, em graus diferentes, práticas que eles consideram inovadoras. "Passar um texto no quadro" e pedir para os alunos copiarem ainda acontecia com frequência. Mas é preciso saber que livros didáticos, ali, raramente chegam para todos os alunos e na data certa. Estávamos em agosto daquele ano e apenas um pacote com 25 livros didáticos destinados a alunos de $5^{\circ}$ ano tinha chegado. Laurinda, responsável também pela secretaria da escola regular, disse que para evitar brigas entre as crianças, haviam decidido não distribuir para ninguém. Assim, em todas as disciplinas as atividades começavam, invariavelmente, pelo professor colocando o enunciado do exercício na lousa e os alunos copiando-o. Algumas vezes, com os mais velhos, essa rotina era substituída por um ditado do enunciado. Como tratava-se de turmas mutisseriadas, com frequência a lousa era dividida, cada parte dela com um enunciado para alunos de um determinado ano. Nas duas turmas de ensino fundamental I, essa etapa tomava muitas vezes já um terço do tempo da atividade.

Mas passado esse momento de cópia, pude observar diferentes estratégias de trabalho postas em prática. Considerando apenas atividades que envolviam leitura (seja nas aulas de português ou de outras disciplinas), observei: discussão em pequenos grupos sobre um texto que havia sido apresentado em aula, seguida da discussão com toda a turma mediada pela professora; leitura em voz alta e em jogral do texto; estudo do vocabulário do texto em pequenos grupos e, em seguida, com toda a turma; discussão coletiva do texto em que a professora fazia perguntas aos alunos, ligando o tema do texto à realidade local (por exemplo, em um texto sobre pontos cardeais e localização espacial com ajuda de mapas, Laurinda pergunta aos alunos "Mas e antigamente, quando meu pai ou meu avô caçavam no mato, como faziam pra não se perder?"); discussão coletiva do texto, em que a professora ajuda os alunos a interpretálo, através de perguntas ("Quem é o personagem principal dessa história que a gente leu?"; “O que ele fez com a irmãzinha dele?" etc.); chamar alunos na frente para apresentar o que compreenderam do texto; pedir que escrevessem um "comentário" sobre o texto lido, dando sua opinião sobre ele. Como essas estratégias deixam entrever, a participação dos alunos na aula era constantemente estimulada. Quando um assunto era apresentado, os professores sempre 
faziam perguntas à turma ou a um aluno em particular ("Vimos a rotação. Ela vem junto com um outro movimento da terra, vocês lembram qual é?"; "E os continentes, Walderson, você pode me dizer quais são?") ou então, como em tantas escolas (e praticamente só nelas...), começam uma frase e esperam que os alunos terminem ("Vamos falar da escravi... dão"). Nos exercícios de matemática, estratégias como jogos, trabalho em grupo, pequenas competições com "prendas a pagar" ou prêmios a receber também aconteciam.

Se considerarmos a experiência escolar com a leitura destes professores, marcada, de acordo com sua memória, pela omnipresença da cópia e a ausência de outros dispositivos pedagógicos, suas práticas docentes atuais são mais variadas e deveriam promover o desenvolvimento de um maior número de habilidades dos alunos, notadamente no que se refere a interpretação de textos. No entanto, essa mudança, que me parece sem dúvida um avanço no sentido de promover uma aprendizagem da leitura que vá além da decodificação das palavras, precisa ser posta na balança com outro dado oriundo destas observações. Se o repertório de atividades dos professores parece ter se ampliado, o domínio que eles têm do conteúdo mesmo da matéria que está sendo ensinada, pode representar um limite à ampliação efetiva das aprendizagens dos alunos. A mesma professora que promove discussões coletivas sobre o sentido do texto escrito na lousa, nem sempre demonstra entender completamente, ela mesma, o sentido de tal texto. Isso fica visível quando ela não se dá conta de que, no meio do texto que lê junto com os alunos em voz alta, há uma frase sem sentido (provavelmente copiada com erros) e uma palavra inexistente. $\mathrm{Ou}$ ainda quando ela não corrige uma interpretação errônea que um aluno faz do texto, nem seus erros gramaticais e ortográficos.

Meu objetivo neste artigo não é discutir as implicações da formação dos professores, ou da falta dela, no desempenho escolar dos alunos. Apresento apenas alguns traços gerais das aulas que assisti para que o leitor possa perceber as lógicas de interação que se estabelecem entre professores e alunos. Nesse sentido, importa ainda informar que os quatro professores que observei incorporavam certos princípios que podemos chamar de democráticos na relação com os alunos. Na época em que estudaram, como lembra Vânia, "não existia isso da 'opinião do aluno' não. Mas quando... Era o professor ali na frente pra passar os temas e pronto". Já em suas próprias aulas, Vânia e Carlos, por exemplo, após apresentarem para alunos do Ensino Fundamental II como pretendiam realizar a avaliação de uma disciplina, perguntaram aos alunos se eles tinham alguma outra sugestão ou se gostariam que a avaliação fosse em algum ponto diferente. Na turma de Vânia, os alunos sugeriram então que o seminário final fosse apresentado em duplas (Vânia havia sugerido um seminário individual), e ela aceitou. Nessas mesmas turmas, e mesmo para as crianças de $4^{\circ}$ e $5^{\circ}$ ano, com frequência antes de começar a atividade, a professora perguntava se eles preferiam que ela colocasse a atividade na lousa ou se queriam ditado. Com os alunos do Fundamental I, ambas as professoras costumavam escolher junto com os alunos a canção da manhã e às vezes uma história que seria contada.

Por fim, é importante dizer que, durante minhas observações, não presenciei nenhum tipo de punição aplicada aos alunos. Crianças conversando entre si enquanto a professora falava (em baixo tom de voz), levantando de seus lugares para falar ou mostrar algo a seus colegas ou para ir ao banheiro, eram cenas comuns. As professoras proferiam por vezes discursos gerais sobre a importância de prestar atenção e "deixar as brincadeiras lá fora [da sala de aula]", mas poucas vezes repreenderam nominalmente algum aluno. Carlos 
13. Uma versão do conto pode ser lida em: https:// www.acessaber.com.br/wpcontent/uploads/2016/03/ interpretacao-de-texto_a-lendado-pregui\% $\mathrm{C}_{3} \%$ A70so-4\% $\mathrm{C}_{2} \% \mathrm{BA}$ ou- $5 \% \mathrm{C}_{2} \% \mathrm{BA}-$ anos.pdf
14. Os nomes de localidades citadas pelas crianças ou professores também foram alterados. era um pouco mais severo que suas colegas, mas tampouco, pelo menos em minha presença, houve punições em suas aulas.

A atitude que considera a opinião do outro e estimula a sua participação contrasta com aquela que os adultos na região costumam ter na relação com as crianças, sejam elas seus filhos ou não. Como já mencionei, as professoras e o professor das escolas são adultos da comunidade, eles não são "forasteiros", mas é interessante notar que eles parecem adotar, em aula, uma postura específica, que não reproduzem fora deste espaço. De fato, em interações cotidianas na comunidade, e mesmo em reuniões com os pais sobre a escola (e na escola) não os vi adotar essa postura. Vejamos então como as crianças e jovens se posicionam nesse cenário.

\section{Interações entre professores e alunos e de alunos entre si}

Conversando sobre a educação de seus filhos e netos, disse-me uma vez uma senhora de idade nesta mesma comunidade: "Criança é igual gado. Vai até onde a gente põe a cerca." Ela enfatizava, na conversa, a importância das "cercas", ou seja dos limites que ela, como tantos ali, acham fundamental que sejam postos, e bem mantidos, para que uma criança seja bem educada.

Diante do clima sem sombra de dúvida mais aberto a sua participação que era o da escola (com relação às interações adulto-criança na comunidade), as crianças que, fora deste espaço escolar, raríssimas vezes vi interrompendo um adulto, que poucas vezes vi fazendo perguntas a eles, pareciam, de fato, ocupar tranquilamente esse espaço suplementar de ação que lhes era ofertado. Se fora da escola, para aprender, raramente ousariam perguntar algo que não haviam entendido ou para o qual gostariam de uma precisão, em sala de aula, fazer isso não causava constrangimentos. Abaixo apresento quatro situações que mostram esse tipo de interação, duas envolvendo professoras e alunos e duas entre alunos.

\section{$1^{\underline{a}}$. situação: o conto do preguiçoso, turma de Fundamental I, escola indígena}

Numa quarta-feira pela manhã, após ter cantado duas músicas com as crianças, Vânia diz que tem achado alguns alunos um pouco preguiçosos na hora de fazer os exercícios. Ela avisa então que irá contar uma história para ajudar a espantar essa preguiça, "o conto do preguiçoso". ${ }^{13}$ Mas ainda no início da narrativa, Jorliane (8 anos) a interrompe e diz: "Professora, lá na minha casa tem uma preguiça no quintal". A professora não a repreende, escuta e responde: "É?" E a menina termina seu comentário: "Os meninos ali da frente jogaram bombinha nela." Em seguida, outros alunos contam casos de encontros ou interações com animais (uma cobra que apareceu no quintal, um irmão que "judiou" de um pintinho...). A professora escuta cada um até que termine, às vezes faz perguntas para entender melhor a história ("E aí, o que vocês fizeram? Mataram ela?"; "Onde era isso?"). Depois de ouvir diversas histórias, ela retoma o conto ("Então, vamos voltar para a história do preguiçoso?) e o termina. Pergunta então às crianças "O que vocês acharam? Que lição nós podemos tirar daqui?". Mas as crianças pareciam ainda mais envolvidas com o tema das conversas não planejadas que haviam emergido sobre animais. Então, depois de alguns segundos de silêncio, Andressa (9 anos) diz: “Ei, professora lá em Igarapé Grande ${ }^{14}$ tinha uma cobra que o menino pegou num pau e queria jogar na gente. Aí o Andrei disse que era pra ele parar e ele não parou". A professora não a corta e não retoma sua discussão sobre a "moral" 
da história do preguiçoso. "Menino tolo, desobediente, né?", responde a professora à Andressa. A conversa segue, e das cobras naturais, o grupo passa a falar de cobras encantadas, o que rende mais de 20 minutos de conversa (até ali, desde o início da narração do conto pela professora, sete minutos haviam transcorrido). A professora se mostra extremamente paciente com as versões, por vezes dificilmente compreensíveis ou audíveis (os mais tímidos falam baixinho), que narram as crianças. Mostra-se atenta à fala de cada um, faz comentários e perguntas sem interrompê-los. Ela também narra algumas histórias com temas afins.

Contar histórias de animais encantados é extremamente comum na região. O que não é comum é a forma que tomou a "sessão de histórias" na aula de Vânia. Adultos e crianças conhecem e contam diversas dessas histórias, mas, fora da escola, os adultos não costumam parar para ouvir as narrativas das crianças. Os mais novos sim, ouvem e observam com atenção a performance dos adultos, mas jamais os interromperiam. E quando as crianças brincam de contar histórias entre elas (o que fazem com frequência), as mais hábeis detêm a fala e engatam uma narração na outra, enquanto aquelas que não "se garantem" ainda, pouco ousam pegar a palavra (Medaets, 2019). A postura de Vânia, deixando-se ser interrompida e mostrando-se paciente e interessada mesmo pelas histórias dos narradores mais inseguros, contrasta não só com aquela dos adultos na comunidade, mas também com a das crianças-narradoras, em grupos da brincadeira de narração entre pares.

Poderíamos imaginar que as crianças, pouco habituadas a essa postura receptiva, atenta e tolerante com suas hesitações, ficassem por demais tímidas e não ousassem se apropriar da fala. Mas nessa sessão extra-ordinária de histórias, os menores ou menos experientes ocupam o espaço que lhes é aberto. Disputam a atenção de Vânia: "Professora, professora", e expõem narrativas que, em outros contextos, costumam ser sancionadas. Com perguntas apoiadoras de Vânia, algumas crianças conseguem prolongar a narrativa, como no diálogo abaixo entre Alex (6 anos) e a professora:

Alex: "Professora eu, eu tenho uma história de cobra grande também."

Professora: "É?"

Alex: “É que..., é que lá em Cajaúba tinha uma cobra. Em Cajaúba não, no meio do rio parece".

Professora: "Você conhece alguém que viu?"

Outra criança: "O vovô já viu a cobra grande".

Alex: "O menino que, a irmã dele contou que num dia que ele foi com o filho, com os dois filhos lá pro meio do rio... pescar."

Professora: "É? E como foi quando eles tavam lá?"

Alex: "Quando chegou, eles viram aquele bucho assim. Aí a cobra puxou, ela puxou a canoa deles. Aí o pai foi tentar tirar ele de dentro da água, aí a cobra pegou, e aí eles foram embora."

Aquele parece também ser o espaço propício para que as crianças sejam guiadas em suas narrativas, recebendo correções ou precisões da professora ou tirando dúvidas, como se vê no dialogo abaixo.

Marliane (7 anos) : “Professora a vovó contou da Mãe d’Água. Que já tava quase ficando de noite..."

Professora: "Seis horas. É a hora que os pajés dizem que é a hora imprópria. Às seis e ao meio dia."

Marliane: "Aí ela foi tomando banho, aí ela viu uma ondona! Aí ela, ela quase ficou 
doida.."

Professora: "É a dona Barrenta."

Jonatan (8 anos): "Barrenta?"

Professora: “É a dona dali daquele lugar. Agora ela foi ali pr’aquela parte do porto, mais pr'ali (indica com a mão). Tanto que agente vê lá, que só é já aquele barro branco, né? Então ela se mudou pra lá, a dona Barrenta."

Camilly (9 anos): "Quem é a dona Barrenta?

Professora: "É a dona de lá daquele porto lá".

Marliane: "É uma mulher?"

Professora: "É uma mulher".

Jonatan: "Ei professora, ela é igual uma cobra e quando chega na terra que ela vira coisa, vira gente?"

Professora: "Não esse é a do Honorato, essa da cobra. É outra história já."

\section{2ํ. Situação: aula de História, turma de Fundamental II, escola regular}

Não era sempre que as crianças, e sobretudo os jovens do fundamental II, participavam de maneira tão intensa. Em muitos momentos, professores expunham conteúdos, davam explicações e os alunos ouviam em silêncio, ou, com mais frequência, fazendo comentários entre si ou ditos para provocar risos de outros alunos, e não dirigidos à professora ou ao professor. Mas o que me parece importante destacar, é que uma relação baseada em um código de conduta diferente daquele em vigor fora da escola, passa, dentro dela, a fazer parte do repertório de possíveis para as crianças, os jovens e para os adultos que são os professores. Como a interação que vemos abaixo, entre Laurinda e seus alunos de $6^{\circ}$ e $7^{\circ}$ ano.

Numa aula de História, falando sobre as mudanças que vão acontecendo nas sociedades com o passar do tempo, Carmem menciona o decréscimo do número de filhos por casal que ocorreu no Brasil, e na comunidade onde vivem. Vemos como "um assunto vai puxando o outro", com a participação dos alunos, que intervém num tom bastante descontraído:

Professora: “Antes era muito filho que a gente tinha, Deus o livre! Porque também não tinha remédio... Ou, se tinha, não tinha chegado aqui. Hoje em dia não, o casal se planeja, vai ter um, dois. Né?"

Jamilton (11 anos): "Professora teve uma mulher que teve cinco filhos na barriga ao mesmo tempo, né?"

Professora: "É?"

Jamilton: "Eles nasceram parecia um ratinho. Lá em casa a gente assistiu, passou no programa".

Professora: "Humm. É... Porque depois de ter, tem que cuidar, né? Filho não é só pra botar no mundo! E quando a gente tem muito, olha, às vezes é obrigada a dar as crianças, não é mesmo?"

Anderson (12 anos): "Professora, tem uma mulher lá no Igarapé Grande que deu duas filhas dela pra uma mulher, uma mulher lá de Santarém"

Professora: "Pois é, então. Já pensaram? Porque olha o sarampo, quando pega, pega em todo mundo. Pega mesmo. E se não tiver vacina, o que acontece?"

Anderson: "Morre."

Professora: "Morre mesmo. Por isso, hoje em dia, a importância da vacina..." Jamilton: “Tchan, já só na bunda dele!” Alunos e professora riem. 
$3^{\underline{a}}$ situação: interação entre duas meninas, ensino fundamental I, escola regular

Quando as crianças interagem sem a interferência dos professores, também o fazem de uma maneira muito própria ao ambiente escolar. Professora Carmem lê, e em seguida põe no quadro, uma parlenda para que os alunos do $1^{\circ}$ ano copiem.

\section{Corre ratinho, \\ Que o gato tem fome, \\ Corre ratinho, \\ Que o gato te come.}

Fábia ( $2^{\mathrm{o}}$ ano), vendo que Suzanne ( $1^{\mathrm{o}}$ ano) copiava muito devagar, senta-se na sua mesa e pergunta "Tu quer ajuda?". Suzanne faz que sim com a cabeça e Fábia começa a copiar no caderno de Suzanne, que acompanha atenta os gestos da mais velha. Quando Fábia muda de linha, Suzanne pergunta: "onde tá?" Fábia lê o verso de cima, seguindo com o dedo a leitura. Ao final da cópia, Fábia volta para a sua carteira, duas atrás de Suzanne. Suzanne fica olhando concentrada o texto em seu caderno, tentando ler. Recita o verso em voz baixa, como se estivesse lendo, seguindo com dedo, mas a palavra que pronuncia não coincide com aquela que indica o dedo. Olha para traz, buscando Fábia, que percebe o olhar da amiga e volta até sua mesa. "Tu pode ler?", pede Suzanne. Fábia faz novamente a leitura da parlenda, seguindo com o dedo. Depois as duas passam a folhear juntas o caderno de Suzanne, olhando diferentes textos e exercícios ali. Ao ver, num cabeçalho, o nome da escola copiado com um erro, Suzanne desconfia que há um problema e pergunta: "Não tá errado isso daqui?". "É mesmo!”, diz Fábia, já pegando a borracha e começando a apagar a letra incorreta. Pede então que Suzanne coloque a letra certa: "Põe um O aí." “Como faz o O mesmo?", Suzanne pergunta. "É uma bolinha”, responde Fábia, fazendo o movimento no ar. Suzanne pega o lápis e escreve lentamente o "O" no lugar certo. As duas continuam alguns minutos na mesma mesa, esperando a professora passar um novo exercício.

\section{$4^{a}$ situação: exercício de matemática, turma de fundamental I, escola indígena}

Vânia havia passado um exercício de matemática para seus alunos de $4^{\circ} \mathrm{e}$ $5^{\circ}$ ano que consistia em escrever como se deve pronunciar certas frações. $\mathrm{Na}$ aula anterior, ela havia ensinado como ler frações com denominador até dez (um meio, um terço, um quarto, etc.) e dito que a partir do número 11 como denominador usamos a palavra "avos" (um onze avos, um doze avos, etc.). Os alunos copiavam o exercício e tentavam começar a resolver, discutindo entre si.

Jederson (10 anos, $5^{\mathbf{0}}$ ano), escreveu, à sua maneira, as frações com denominadores menores que dez. Mas diante da fração não sabia como fazer. Foi então até a mesa de Andrielly ( 9 anos, $4^{\circ}$ ano) e pediu: "Como é esse aqui?" Andrielly explicou: “do 10 pra frente, já pega avos". “Pega não!”, contestou seu vizinho de mesa, Jubert (10 anos, 4 ano), "Pega sim", devolveu Andrielly assertiva. E passou instruções a Jederson: "Aqui tu põe cinco, com letra, e embaixo tu põe onze e põe avos." Jederson acha um cantinho da mesa da colega para seu caderno e escreve: . Mostra a Andrielly: "Assim?" “Não", ela replica e apaga o que Jederson tinha feito. Pega então a mão do menino, escreve junto com ele a palavra "cinco" e faz o traço abaixo. Em seguida re-explica: "Escreve a palavra cinco, passa o traço e escreve embaixo a palavra onze e a palavra 
avos". Jederson termina: . Andrielly indica com a cabeça que agora está certo. Jubert mostra então o que a fez a Andrielly: “Taí: ". “Não, avos aqui não! Só em baixo!", responde, brava. Jubert corrige. As crianças verão na correção da professora, no dia seguinte, que deveriam ter escrito "Cinco onze avos", tudo na mesma linha e sem o traço. Jubert provocará então Andrielly “Tu nem sabia!”.

Esse tipo de interação, com pedidos de ajuda mais ou menos explícitos, com crianças mais experientes assumindo o papel de guia daquelas que são menos, são raras fora da escola. Em alguma medida, acontecem, claro, sobretudo com crianças de idades e competências similares. Mas, fora da escola, é muito mais comum ouvir e ver os mais experientes simplesmente afastarem (ou se afastarem) dos menos experientes ou cortarem-nos secamente ("E o quê já!"). O que explica que, ao perguntar como aprenderam alguma coisa, seja tão comum ouvir dos moradores da região que não aprenderam "de ninguém", mas sozinhos. Na escola as regras são outras e todos parecem se acomodar disso sem pesar.

\section{Discussão com a literatura e conclusão}

Quando estava em campo durante o doutorado estabeleci com as crianças uma relação diferente daquela que os adultos na região tinham com elas. Isso era indispensável já que meu objetivo era me aproximar das ocupações e preocupações delas, coisa que meus hóspedes adultos achavam "tolice de menino". Reparei na época quão rápidas elas foram em perceber essa diferença, e explorar seus limites, sem que tivéssemos discutido a respeito. Me tiravam da cama quando achavam que estava demorando a me acordar, me interrompiam à vontade para falar o que lhes interessava, pegavam meu caderno de campo para desenhar, decidiam (depois de alguns meses de convivência) nosso programa de cada dia. Nada disso faziam com outros adultos, e não faziam também mesmo comigo, desde que estivéssemos na presença de outros adultos. Elas trocavam de código de conduta rápida e sutilmente, bastava alguém se aproximar e devolviam meu caderno, por exemplo, ou paravam momentaneamente de falar. A antropóloga Flávia Pires viveu algo semelhante, quando, na casa que alugou para morar na cidade de Catingueira, permitia que as crianças pulassem no sofá, o que não podiam de jeito nenhum fazer em suas próprias casas. Pires relata que as crianças sabiam que, para adultos de Catingueira, pular no sofá não é um comportamento adequado, e quando as crianças o faziam, não poupavam entusiasmo pois era "como se soubessem que aquela alegria era daquele tipo proibida, que só pode durar muito pouco" (2007, p. 232).

Tanto Pires quanto eu abrimos espaço para que estes "novos comportamentos" emergissem. Na relação que buscávamos estabelecer com nossos interlocutores crianças, informadas por discussões teóricas e metodológicas da prática de pesquisa com crianças em ciências sociais, essa abertura fazia sentido. Deveria permitir - e acredito que tenha de fato permitido - que nos aproximássemos mais dos nossos objetivos.

Os professores das escolas que observei também tiveram, em diferentes momentos de sua formação, acesso a discussões teóricas e metodológicas sobre a prática docente. Sem dúvida influenciados por essas reflexões (e sem dúvida também, incorporando outras referências), também fizeram escolhas e estabeleceram rotinas. Construíram, assim, as bases de uma relação com as crianças e jovens que é bastante diferente daquela que eles mesmos, no passado, 
experimentaram enquanto alunos, e que difere também daquela que eles mantém atualmente com as crianças, fora da escola. ${ }^{15}$ As crianças e jovens, por sua vez, parecem mudar de conduta com a mesma facilidade que pessoas bilíngues trocam de idioma em função do ambiente.

Muito já foi escrito sobre diferenças e similaridades de práticas de crianças dentro e fora da escola (em suas famílias e comunidades), em particular para crianças de classes populares, minorias culturais ou populações nativas. Nos Estados-Unidos, em meados do século XX, contrapondo-se a teorias racistas que explicavam em termos biológicos as maiores dificuldades que crianças indígenas e negras encontravam na escola, vemos surgir uma explicação que fala de "carência" ou "déficit cultural"16 - um correlato da "cultura da pobreza" (Lewis, 1966) aplicada à educação. Para os teóricos do "déficit cultural", as crianças indígenas, negras ou de classes populares seriam expostas em suas famílias e comunidades a experiências cognitivas e linguísticas "menos complexas" que aquelas veiculadas pela escola e por isso teriam dificuldade de acompanhar as atividades desta instituição. A partir dos anos 1960, buscando romper com essa lógica evolucionista, pesquisadores do campo da antropologia da educação norte-americana, influenciados pelas ideias da sociolinguística de Dell Hymes (1974), propõem pensar em "descontinuidades culturais" entre as práticas de certas famílias e aquelas da escola, ou em "desajustes" entre esses dois espaços, sem que esse desencontro (mismatch) implique em considerar nenhum desses espaços como superior ou mais complexo que o outro, mas apenas diferentes. ${ }^{17}$ As crianças de classes populares, crianças nativas ou pertencentes a minorias étnicas, chegariam à escola com uma "cultura invisível" (Philips, 1993) - entendida como valores, estilos de fala (speech styles) e maneiras de se comportar - e habituadas a uma "estrutura de participação" (Erickson, 1982) distinta, e que por vezes entraria em conflito com os princípios organizadores da pedagogia escolar. Por "estruturas de participação" ou, nos termos de Elsie Rockwell (2018, p. 220), "lógicas de interação", estes autores entendem as regras ou maneiras comum de se interagir e se comunicar num determinado grupo (falar ou não olhando nos olhos de um adulto, sentir-se ou não autorizado a interromper pessoas de mesma idade ou de idade diferente, falar ou não ao mesmo tempo que seu interlocutor, etc.).

Estes pesquisadores foram por sua vez duramente criticados por John Ogbu (1982) para quem a relação histórica e política das populações estudadas com a sociedade englobante está ausente das análises em termos de "(des)continuidades culturais". Estas pesquisas teriam, segundo Ogbu, um ângulo de análise demasiadamente microetnográfico. Levando em conta e adiante esse debate, uma série de autores, de diversas nacionalidades, tentou incorporar ganhos analíticos e mostrar pontos de desacordo tanto com relação aos trabalhos da linha das "descontinuidades culturais" quanto daqueles de Obgu (Erickson, 1982; Trueba, 1989; Foley, 1991; Hemphill e Snow, 1996; Gomes, 2006; Hays, 2016; Rockwell, 2018).

No contexto brasileiro, Ana Gomes recupera as grandes linhas dessa discussão para pensar a "cultura escolar que está se configurando entre os Xacriabá" (2006, p. 324). E mostra como tanto a ideia da presença na escola de uma "cultura invisível" faz sentido para pensar a apropriação que os Xacriabá tem feito desta instituição (indigenizado-a, por exemplo, quando professoras xacriabá fazem bons alunos repetirem de ano por considerarem que eles poderão assim ajudar os outros a progredirem), como faz sentido incorporar na análise pontos para os quais chama atenção Ogbu, com relação ao contexto político das relações entre os Xacriabá e os órgãos governamentais com os quais têm que
15. Porque todas essas percepções estavam ainda muito frescas e pouco claras para mim durante esta estadia em campo em 2016, não cheguei a conversar com os professores sobre isso e perguntar-lhes se percebem e como percebem essa diferença de comportamento que têm dentro e fora da escola.

16. Richard Valencia (1997) apresenta detalhadamente o pensamento dos autores dessa perspectiva, suas bases teóricas e as discussões na cena acadêmica da época.

17. Para uma síntese analítica dos principais trabalhos nessa linha, ver Van Zanten e AndersonLevitt (1992, pp. 86-88). 
18. Descrevendo respectivamente, a situação dos Tubinambá de Valença (Bahia) e dos Xacriabá (Minas Gerais).

19. Considerando as reflexões sobre a cultura com aspas de $\mathrm{Ma}$ nuela Carneiro da Cunha (2009). lidar (quando eles se veem "na constrição de elaborar formas de torná-la [sua cultura] pública de maneira à responder aos estereótipos do que é considerado uma 'autêntica cultura indígena'”, Gomes, 2006, p. 325).

Partindo de outro referencial teórico, dialogando com a noção de fronteira tal como ela é pensada por Fredrik Barth (1998 [1969]), Antonella Tassinari (2001) propõe pensar a escola indígena como um espaço de fronteira, onde projetos, conhecimentos e interesses distintos se encontram e se negociam. Nesse sentido, alguns povos indígenas no Brasil têm pensado a escola como um espaço de fortalecimento de sua própria língua e tradições (Álvares, 2004; Santana e Cohn, 2016) ${ }^{18}$ e outros, no sentido inverso, a consideram e se organizam para que ela seja um espaço primordial de contato com os "conhecimentos dos brancos" (Gallois, 2001; Tassinari e Cohn, 2009; Cohn, 2016). Clarice Cohn mostra que os Xicrin não somente reconhecem que a forma escolar é muito diversa do modo como eles mesmos concebem o conhecimento, mas destaca que "salta aos olhos o empenho das crianças em se adaptar a esta forma escolar" (2016, p. 322), assim como o empenho dos adultos em fazer da escola um lugar onde se "aprende a lidar com a alteridade" (Cohn, p. 325). Entre esses dois polos (a escola como espaço da diferença ou espaço de manutenção da própria cultura, com e sem aspas) ${ }_{1}^{19}$ são, claro, múltiplas e cheias de matizes e de soluções inesperadas as experiências de apropriação da escola por populações indígenas, que contam, vale lembrar, cada vez mais com professores eles mesmos indígenas.

No caso dos ribeirinhos e indígenas do Baixo Tapajós, a diferença entre os modos de transmitir e de aprender escolares e não escolares é, como mostrei, importante. Se fora da escola as crianças raramente interrompem a fala de um adulto e não costumam fazer muitas perguntas, nas aulas, dadas por professores da própria comunidade, esse tipo de interação é frequente. Os espaços de formação pelos quais passaram os professores parecem ter influenciado a maneira com que eles organizam essa interação com os alunos. Os professores relatam ter sido constantemente estimulados, nas formações universitárias que realizaram, a abandonar um ensino que não promove a participação dos alunos, indo de encontro portanto a sua própria experiência escolar e às maneiras com que atualmente se relacionam com as crianças fora da escola.

É certo que há também similitudes e um trânsito de assuntos e maneiras de se comportar entre dentro e fora da escola no Tapajós. No caso estudado, vemos essa circulação, por exemplo, quando as professoras abrem espaço para falar sobre os encantados ou ainda sobre as experiências de caça e de localização na mata dos adultos da comunidade. Meu intuito não é de sugerir que a escola no Baixo Tapajós seja um espaço fechado às influências do que acontece fora dela. Pelo contrário, essas mesmas formações que incitam os professores a abrirem mais espaço à participação dos alunos, os impele também a aumentar o diálogo com as "realidades locais". O que sugiro é que, no que se refere à "estrutura de participação" (Erickson, 1982) há uma diferença notável.

A escola é um espaço de transmissão de saberes ("conteúdos"), mas também de normas, valores e posturas (uma certa maneira de ouvir, de participar, de pedir e receber ajuda, de se manter sentado, etc.). ${ }^{20}$ Nesse sentido, a cultura escolar que tem se construído no Baixo Tapajós, promove modos de interagir onde a participação das crianças têm ganhado mais espaço. Na continuidade da pesquisa será interessante pensar, junto com os professores e as crianças da região, se e como essa lógica de interação sai das escolas e ganha, ou não, espaço nas conversas cotidianas. 


\section{Financiamento:}

$\mathrm{O}$ trabalho de campo realizado no âmbito desta pesquisa contou com financiamento CAPES/PROEX, do Programa de Pós-graduação em Educação da Pontifícia Universidade Católica do Rio Grande do Sul.

Sobre la autora:

Chantal Medaets é mestre em Educação e doutora em Antropologia pela Universidade Paris Descartes. É atualmente pós-doutoranda CAPES/PNPD na Faculdade de Educação da Unicamp. 


\section{Q Referências bibliográficas}

"Álvares, M. (2004). Kitoko Maxakali: a criança indígena e os processos de formação, aprendizagem e escolarização. Revista AntHropológicas,15(1), 49-78.

» Barth, F. (1998 [1969]). Ethnic groups and boundaries: the social organization of culture difference. Long Grove: Waveland Press.

" Carneiro da Cunha, M. (2009). Cultura com aspas. São Paulo: Cosac Naify.

" Cohn, C. (2016). A cultura nas escola indígenas. Em M. C. Cunha e P. Cesarino (Orgs.), Políticas culturais e povos indigenas (pp. 313-338). São Paulo: UNESP.

»Delbos, G., y Jorion, P. (1984). La transmission des savoirs. Paris: Éditions de la Maison des Sciences de l'Homme.

»Erickson, F. (1982). Classroom discourse as improvisation: the relationship between academic task structure and social participation structure in lessons. Em L. C. Wilkenson (Ed.), Communicating the classroom (pp. 153-181). Nova York: Academic Press.

" Foley, D. (1991). Reconsidering anthropological explanations of ethnic school failure. Anthropology and Education Quarterly, 22, 6o-86.

»Gallois, D. (2001). Programa de educação Waiãpi: reinvindicações indígenas versus modeles de escolas. Em A. Lopes da Silva y M. Ferreira (Eds.), Antropologia, história e educação (pp. 44-70). São Paulo: Editora Global.

» Gomes, A. M. R. (2006). O processo de escolarização entre os Xakriabá: explorando alternativas de análise na antropologia da educação. Revista Brasileira de Educação, 11(32), 316327.

" Hays, J. (2016). À qui appartient l'éducation ? Les Écoles de village et les Jul'hoansi de Nyae Nyae, Namibie. Cahiers de la recherche sur l'éducation et les savoirs, 15, 2751.

» Hemphill, L. e Snow, C. (1996). Language and literacy development: Discontinuities and differences. Em D. Olson e N. Torrance (Eds.), The Handbook of Education and Human Development (pp. 173-213). Oxford: Blackwell.

" Hymes, D. (1974). Foundations in sociolinguistics: an ethnographic approach. Philadelphia: University of Pennsylvania Press.

" Lave, J. (1988). Cognition in practice: mind, mathematics and culture in everyday life. Cambridge: Cambridge University Press.

"Lewis, O. (1966). La vida: a Puerto Rican family in the culture of poverty. Nova York: Random House.

»Mahalem de Lima, L. (2015). No Arapiuns, entre verdadeiros e -ranas: Sobre as lógicas, as organizações e os movimentos dos espaços do político (Thèse de doctorat). Universidade de São Paulo, Faculdade de Filosofia, Letras e Ciências Humanas, São Paulo.

» Medaets, C. (2013). "A prometida": normas educativas e práticas disciplinares em comunidades ribeirinhas da região do Tapajós, estado do Pará. Civitas, 13(2), e1e14.

"Medaets, C. (2015). Malgré les adultes: une ethnographie des situations non scolaires d'apprentissage chez les habitants du bas-Tapajós (Amazonie brésilienne) (Tese de Doutorado). Université Paris Descartes, Paris. 
" Medaets, C. (2016). Despite Adults: Learning Experiences on the Tapajós River Banks. Ethos, 44(3), 248-268.

»Medaets, C. (2017). Apprentissages des enfants confiés : contrôle émotionnel et expérience de la soumission. Em A. Pierrot, I. de M. Carvalho y C. Medaets (éds), Domination et apprentissage. Anthropologie des formes de la transmission Culturelle (pp. 145-158). Paris: Hermann.

" Medaets, C. (2019). “Bora da história ?” : un jeu de narrations entre enfants dans le bas Tapajós (Amazonie brésilienne). Strenae, 15 (on-line). Disponível em https://journals. openedition.org/strenae/3458 . Acessado em 20/10/2019.

"Odden, H. (2007). The Acquisition of Cultural Knowledge of Hierarchy by Samoan Children (Tese de doutorado), Emory University, Emory, Atlanta.

» Ogbu, J. (1982). Cultural discontinuities and schooling. Anthropology and Education Quarterly, 13, 290-307.

" Paradise, R., y Rogoff, B. (2009). Side by Side: Learning by Observing and Pitching In. Ethos, 37(1), 102138.

»Perrenoud, P. (1994). Métier d'élève et sens du travail scolaire, Paris: ESF.

"Philips, S. (1983). The invisible culture: communication in classroom and community on the Warm Springs Indian Reservation. Prospect Heights: Waveland Press.

"Pires, F. (2007). Ser adulta e pesquisar crianças: explorando possibilidades metodológicas na pesquisa antropológica. Revista de antropologia, 50(1), 225270.

»Rockwell, E. (2018). Vivir entre escuelas: relatos y presencias. Antología esencial. Buenos Aires: CLACSO.

» Rogoff, B., Paradise, R., Arauz, R. M., Correa-Chávez, M. e Angelillo, C. (2003). Firsthand Learning Through Intent Participation. Annual Review of Psychology, 54(1), 175203.

»Santana, J. V. e Cohn, C. (2016). Formas de Estar na Cultura na e pela Escola: o caso dos indígenas Tupinambá de Olivença/BA. Anthropológicas, 27(1): 218-244.

"Sautchuk, C. E. (2015). Aprendizagem como gênese: prática, skill e individuação. Horizontes Antropológicos, 21(44), 109139.

"Shulist, S. (2018). Transforming indigeneity. Urbanization and language revitalization in the Brazilian Amazon. Toronto: University of Toronto Press.

"Silva, R. C. da e Gomes, A. M. R. (2015). Learning, body and territory among indigenous Xakriabá boys. Horizontes Antropológicos, 21(44), 173200.

» Tassinari, A. (2001) Escola Indígena: Novos horizontes teóricos, novas fronteiras de educação. Em A. Lopes da Silva e M. Ferreira (Eds.), Antropologia, história e educação (pp. 44-70). São Paulo: Editora Global.

" Tassinari, A. (2015). Produzindo corpos ativos: a aprendizagem de crianças indígenas e agricultoras através da participação nas atividades produtivas familiares. Horizontes Antropológicos, 21(44), 141172.

» Tassinari, A. y Cohn, C. (2009). "Opening to the Other”: Schooling among the Karipuna and Mebengokré-Xikrin of Brazil. Anthropology \& Education Quarterly, 4O(2): 150-169.

» Trueba, H. (1989) Raising Silent Voices: Educating the Linguistic Minorities for the 21st Century. Nova York: Newbury House Publishers. 
»Van Zanten, A. e Anderson-Levitt, K. M. (1992). L'Anthropologie de l'éducation aux EtatsUnis : méthodes, théories et applications d'une discipline en évolution. Revue française de pédagogie, 101(1), 79104.

"Valencia, R. (Ed.). (1997). The Evolution of Deficit Thinking: Educational Thought and Practice. London e Washington: The Falmer Press.

» Vaz, F. de A. (2010). A Emergência étnica de povos indígenas no baixo rio Tapajós, Amazônia (Tese de Doutorado). Universidade Federal da Bahia, Programa de Pós Graduação em Ciências Sociais, Salvador. 